\title{
Investigación en el entorno de la pandemia: un ejercicio de reflexión
}

\section{Research in the environment of the pandemic: an exercise in reflection}

\author{
Leonel De Gunther Delgado \\ Universidad de Sonora \\ leonel.degunther@unison.mx \\ https://orcid.org/0000-0002-8075-08 18 \\ Diana Brenscheidt genannt Jost \\ Universidad de Sonora \\ diana.brenscheid+@unison.mx \\ hitps:// orcid.org/0000-0003-3916-1963 \\ Arturo Valencia Ramos \\ Universidad de Sonora \\ arturo.valencia@unison.mx \\ hitps://orcid.org/0000-0003-4604-663X
}

\section{Resumen}

En este artículo se ofrece una reflexión sobre las consecuencias de la pandemia en la investigación en las humanidades y las artes. Se analiza como un fenómeno complejo, es decir, tejido en conjunto con otros datos, hechos o fenómenos, cuyas características visibles lo colocan como un fenómeno que no hemos pensado bien, sin nombre conocido, fuera de las disciplinas y sin normas conocidas, cuyo abordaje requiere algo más que la sola cognición disciplinada. Seguimos para su desarrollo una estrategia dialéctica, como un medio de acceso al conocimiento, no lógico; sino como dispositivo epistemológico. Se analizan en forma de preguntas las bifurcaciones que derivan de las condiciones de la pandemia y ejemplificamos a partir de los estudios de performance y sociológicos, como dispositivos teóricos, una variedad de manifestaciones artísticas en línea que nos permiten preguntarnos por el surgimiento de nuevas formas de ser (fenómenos humanos o artísticos) e, incluso, de un nuevo modo de ser investigador en las humanidades y las artes.

Palabras clave: Investigación, Arte, performance, Pandemia

\section{Abstract}

This paper reflects the consequences of the pandemic on research in the humanities and the arts. First, it is analyzed as a complex phenomenon woven together with other data, facts, or phenomena. Its visible characteristics place it as a phenomenon that we have not thought of well, without a known name, outside disciplines, and without known norms, whose approach requires more than just disciplined cognition. Second, we follow a dialectical strategy for its development, as a means of access to knowledge, not logical but as an epistemological device. Third, we analyze in the form of questions the bifurcations that derive from the 
conditions of the pandemic. Finally, we exemplify from performance studies and sociological ones, as theoretical devices, various artistic manifestations online. Both allow us to ask about the emergence of new ways of being (human or artistic phenomenons) and new ways of being a researcher in the humanities and the arts.

Keywords: Research, Art, Performance Studies, Pandemic.

Nosotros, los de entonces, ya no somos los mismos Pablo Neruda. Poema XX

\section{Introducción}

En este artículo se ofrece una reflexión sobre las consecuencias de la pandemia derivada del virus SARS 2, Covid-19 en la investigación en las humanidades y las artes. Se analiza como un fenómeno complejo, es decir, tejido en conjunto con otros datos, hechos o fenómenos, cuyas características visibles lo colocan como un fenómeno que no hemos pensado bien, sin nombre conocido, fuera de las disciplinas y sin normas conocidas, un fenómeno impensable, indisciplinado, innombrable y enorme, cuyo abordaje requiere algo más que la sola cognición disciplinada. Seguimos para su desarrollo una estrategia dialéctica, como un medio de acceso al conocimiento, no lógico; sino como dispositivo epistemológico (Kennel, 2013; Zemelman 1992). Se analizan en forma de preguntas las bifurcaciones (Wallerstein, 2007) que derivan de las condiciones de la pandemia y ejemplificamos a partir de los estudios del performance (Schechner, 2012) y sociológicos (Reckwitz, 2020), como dispositivos teóricos, una variedad de manifestaciones artísticas en línea que nos permiten preguntarnos por el surgimiento de nuevas formas de ser (Kuhn, 1993; 2000), -fenómenos humanos o artísticos- e, incluso, de un nuevo modo de ser investigador o investigadora en las humanidades y las artes.

\section{Pandemia, investigación, modos de ser y producción artística}

La crisis originada a partir de la pandemia SARS 2, Covid-19 puso a la vista múltiples problemas. Unos de ellos ya conocidos, algunos novedosos y desafiantes y otros más fuera de la norma conocida. Tales problemas sea que se piensen desde su dimensión material o simbólica, desde las disciplinas, desde la vida misma, desde lo individual o desde lo colectivo su conjunción, diversidad y tamaño configura una grave crisis planetaria, donde lo que está en juego es la vida humana como especie. Su solución aún distante en el horizonte cercano invita a afirmar que se trata de una cuestión difícil de pensar, sin nombre conocido, fuera de las disciplinas y sin norma conocida.

Se trata pues de un fenómeno impensable, indisciplinado, innombrable y enorme cuyo abordaje requiere algo más que la sola cognición disciplinada. Demanda, a la par, la incorporación del cuerpo sensible y de la política que la nombra. Pensamiento, cuerpo y plaza pública constituyen una triada que articula 
el pensamiento que piensa, el cuerpo que siente lo pensado y el pensamiento sentido y expresado frente a los otros, cuyos resultados al abordar la pandemia serán provisorios e inciertos seguramente.

La definición kuhniana de crisis expresa parcialmente lo que señalamos: las teorías y métodos disponibles son insuficientes para afrontar los problemas derivados de la pandemia, por lo que requerimos (tal vez) no hacer ciencia normal sino "ciencia extraordinaria" (aunque no sepamos cómo) (Kuhn, 1993, 2000). Una ciencia que echa mano de conocimientos dispersos y disponibles, una ciencia anómala, que no teme la contaminación, hibridación o mestizaje disciplinario en el que circulan saberes de diversa índole sean de carácter parcial o especulativo para la comprensión del fenómeno, pensados por un sujeto que piensa, siente y expresa lo sentido y pensando. Exige algo más de un nosotros inclusivo para construirse como una totalidad concreta (Zemelman, 2005).

Si estamos pensando en la investigación, cabría preguntarse por las bifurcaciones que se hacen visibles. Wallerstein (2007), señalaba que toda sociedad tiene un nacimiento, un desarrollo, y en el punto más alto de ese desarrollo hay puntos de bifurcación que pueden dirigir el cambio o transformación o incluso la defunción de una sociedad. En este sentido, valdría la pena poner la atención en esos puntos de bifurcación que emergen. Por ejemplo, una de las implicaciones fuertes que esto tiene con respecto a la investigación es ¿cuántos profesores/as, funcionarios, estudiantes nos habríamos imaginado que la investigación se mudaría a casa? ¿Y cuantos de nosotros nos habríamos preguntado cuáles serían los saberes necesarios para llevarla a cabo bajo estas circunstancias? Podríamos pensar algunos casos.

La crisis puso al frente la tarea de investigar desde la lógica de aprenderhaciendo y ¿cómo es esto? Se trata de aprender con quien lo hace, con quien lo está haciendo. Es decir, se trata de localizar a un investigador o investigadora que sabe investigar en época de crisis, de pandemia o a un colectivo que, como comunidad pensante, está reflexionado en la acción investigar mientras aprende haciendo. Se trata de la búsqueda infructuosa de un sujeto individual o colectivo inacabado y en formación, de un sujeto inexistente aún. Es posible preguntarnos, ¿qué significa investigar en época de pandemia?, ¿cuáles son la reflexiones y prácticas que posibilitan su desarrollo?, ¿se trata de una nueva subjetividad que se vislumbra en el horizonte cercano?

Las cuestiones reflexivas anteriores, se entrecruzan también con aspectos básicos: contar con una infraestructura mínima (equipo, conectividad), con la transformación de un espacio (la casa) como un espacio de investigación, con la construcción de las formas de interacción con investigadoras e investigadores, con el aprendizaje de plataformas, bases de datos y aplicaciones que permitan la comunicación, el almacenaje y uso de la información y, además, con otras de difícil gestión: las emociones; ser vigilantes de nuestra cognición, de nuestro emocionar y de nuestro decir.

Podemos preguntarnos, además, ¿cuáles son las condiciones reales para la realización de la investigación en estas circunstancias? La universidad como 
institución es un soporte material e inmaterial de la investigación, aun con su cuidado extremo de los bienes escasos que representa el financiamiento. En esas condiciones, la producción de conocimiento en nuestra universidad es escaso en situaciones "normales", difícil será la producción en las condiciones de "excepción" en que nos encontramos.

Aunado a lo anterior, podemos pensar en cómo la universidad piensa la pandemia y qué tipo de prácticas lleva a cabo. Podríamos pensar en que la institución está ausente de la realidad en que se vive la pandemia, en que los profesores y profesoras, investigadores e investigadoras la viven y sobrellevan. Podemos agregar además al Estado, cuyas decisiones, al igual que las universitarias, regeneran nuevos problemas derivados de sus propias acciones. Piénsese en las nuevas reglas del juego para la investigación científica publicada recientemente.

Las preguntas son inagotables, ¿qué potencia tiene la investigación en estas circunstancias, cuya movilidad se encuentra restringida para el trabajo de campo?, ¿se trata de una semilla que, desde la orientación aristotélica, es el árbol en potencia?, ¿cómo se riega, como se desahíja, con que se abona para alcanzar su propósito?

Podríamos preguntarnos, además, ¿qué podemos hacer cuando el conocimiento disponible es inútil o sólo parcialmente útil para comprender el fenómeno que estamos viviendo, en otra pregunta? ¿cómo se conoce lo que cambia y finalmente, reiterar la pregunta: ¿cuáles son los saberes útiles, pertinentes para vivir esta época y la de lo por venir?

Esta postura nos obliga a caminar bajo la crisis y aprender de ella, al menos en busca de una cierta autonomía. Nos obliga a buscar otras lógicas de articulación de saberes. Una visión bio-ética, pertinente y urgente sobre todo ahora, en que la instrumentalización del aparato educativo basado en una lógica de coste beneficio ha dejado fuera procesos formativos como la comprensión de una ética de la vida humana (bio-ética), la articulación de "una unidad compleja ecológica, de vida y de cultura" (Blas-Lahitte y Sánchez-Vázquez, 2011) o de formación de capacidades (Nussbaum, 2012), que integre la cognición al cuerpo, a la política y al entorno, construyendo un sujeto o individuo menos fragmentado en su humanidad.

También, impulsa a pensar en la enseñanza de la condición humana, de la humana condición como aludían Morín, Ciurana, y Motta (2006), de aquello que nos condiciona como humanos. La enseñanza de las múltiples dimensiones de lo humano, no sólo biológicas, químicas, ambientales, religiosas, culturales, sociales, sino humanas como la razón y la sinrazón, el juego, la imaginación, el deseo, la necesidad (que nunca se tocan), esa capacidad de pensarnos dialógicamente, de crear un espacio en el que coexisten dos visiones incompatibles que necesitan mantener su diferencia, pero también articularse para pensarse y también, la articulación de la ciencia y la cultura como mundos complementarios del saber.

Veamos ahora lo que sucede en las representaciones escénicas mientras vivimos en la situación de la pandemia. Muchas de nuestras reflexiones sobre las 
condiciones actuales pueden encontrar eco en situaciones específicas que, si bien podíamos haber imaginado, las imaginamos para un futuro no muy cercano. Pero, he aquí que el tiempo nos alcanza y nos condiciona a nuevas formas de producir y consumir el arte.

De acuerdo con el sociólogo alemán Andreas Reckwitz (2020), los individuos en la modernidad tardía buscan lo singular, lo especial, en lugar de lo común y cotidiano. Esa búsqueda por lo singular - la cual sin duda representa también un factor económico importante -, la asocia de manera primordial con los conciertos y eventos artísticos en vivo, ofreciendo al individuo experiencias fuera de lo común y estandarizado. Ahí el sujeto moderno tardío encuentra satisfacción en su afán por expresar y manifestar su individualidad y unicidad.

Mientras esas experiencias singulares, por la ubicuidad de los medios sociales de comunicación, muchas veces son compartidas con un número (preferentemente) infinito de seguidores, encontramos en los últimos años, por ejemplo, en conciertos de músicos y grupos populares a nivel internacional, la tendencia de controlar esa difusión a través de eventos 'libres de celulares' que promueven a 'vivir el momento'. Aunque queda por debatir si de verdad vivimos mejor el momento si no tenemos un celular en la mano, se manifiesta aquí una tendencia: la experiencia artística vivida, en un lugar y tiempo específico con personas físicamente presentes a mi lado, tiene importancia para nosotros y hasta nos define como sujetos en la modernidad tardía.

Sin duda, la pandemia nos ha cambiado nuestras posibilidades de vivir y adquirir esas experiencias. ¿Podemos todavía hablar de experiencias si no estamos en el mismo lugar como los músicos, bailarines, actores o performers, sino los percibimos a través de una pantalla? Y, para no subestimar el aspecto económico, ¿quién está dispuesto a pagar por un concierto o una obra de teatro transmitido en línea? ¿0 cuánto estamos dispuestos a pagar por el evento online si YouTube nos ofrece sin pago una cantidad de videos o tomas de eventos artísticos?

Los estudios del performance nos han indicado desde hace décadas que un evento artístico (un concierto musical, una función de teatro o de danza, etcétera) empieza mucho antes de que lo identifiquemos como el performance mismo; posiblemente desde el momento en el cual nos alistamos para salir de la casa, y definitivamente en cuanto entramos al lugar del evento, cuando nos sentamos emocionados y expectante por lo que va a empezar en un momento. Richard Schechner (2012) llama a esa fase antes la protorrepresentación e incluye ahí también a los ensayos y otras acciones preliminares por parte de los artistas (p. 355). La protorrepresentación está seguida por la representación pública, cuyo punto de inicio es difícil de definir: ¿empieza el evento cuándo se apagan las luces? ¿Cuándo el intérprete entra al escenario? ¿Cuándo inicia la música, el movimiento, la interpretación? Según el modelo de Schechner, la estructura de un performance termina con las repercusiones, las reseñas y críticas que forman parte de las pláticas, el intercambio de opiniones al salir del evento, o que son publicados de manera inmediata o después en los medios sociales y de comunicación. 
Describiendo esas fases según Schechner, nos damos cuenta no solo de que un performance o un evento artístico en vivo es un proceso mucho más largo que hemos pensado, sino también del que participan una variedad de actores: los intérpretes, el público, el dramaturgo o coreógrafo, hasta - si seguimos a lo que propone Small (1998) - la persona que revisa los boletos de entrada o la que limpia los baños del teatro quienes forman de alguna manera parte del mismo.

Regresando a nuestra situación actual de las artes bajo la contingencia, nos podemos preguntar: ¿aplican esas fases también a un evento virtual? Sin duda, los intérpretes se preparan para su presentación; aunque muchas veces esa presentación, la representación pública según las categorías de Schechner, resulta ser un video grabado y editado con anterioridad. Sin menospreciar el vídeo bien hecho que, en sí, en nuestra opinión, es una obra de arte, lo que identifica a un evento artístico en vivo ahí pierde presencia: el saber que se está haciendo ahora en el mismo momento, siempre con el peligro de que algo no salga como está previsto, resultando en cierta nervosidad, una atención distinta, tanto de los intérpretes como del público consciente de la unicidad de la situación.

Esa atención se siente físicamente en los cuerpos de los intérpretes, sus movimientos, tensiones, relajaciones, o en una reacción o un movimiento raro, extraño, del cual nos damos cuenta inmediatamente y nos hace a los intérpretes tan humanos, reales, hasta empáticos. También, como espectadores, sentimos la atención en nuestros cuerpos mismos, en cómo nos sentamos, nos movemos, cómo reaccionamos espontáneamente si no logramos controlar nuestros cuerpos, así como las reglas formales no escritas de los conciertos y presentaciones teatrales.

Pensando en el público que se conecta para la transmisión en vivo, sin duda las acciones preliminares, la fase de la protorrepresentación del modelo de Schechner, no es la misma. ¿Quién se alista para un concierto o una obra teatral en línea? Muchos de nosotros, probablemente buscamos más bien un lugar cómodo, disfrutamos quizá con una bebida y un snack - en el mundo 'real' de los eventos artísticos generalmente prohibido - la transmisión en línea, y le ponemos tanta atención que no lo vemos en la cocina mientras limpiamos los platos.

La fase después del evento, las repercusiones, empieza en paralelo con el evento dándole likes a los intérpretes, corazones, publicando comentarios, y ahí nos sentimos juntos, fluimos con los demás aplaudiendo virtualmente a los artistas. Esperamos que los vean y que les den satisfacción. Uno como espectador solo se puede imaginar la diferencia entre recibir aplausos virtuales y en físico, todavía en el escenario, sudando, contento o crítico consigo mismo.

Cabe mencionar que las presentaciones de arte en línea nos han afectado también como investigadores. Por una parte, disfrutamos bajo la situación de la pandemia una explosión de eventos académicos en línea, posibilitándonos como nunca antes la participación en conferencias de investigadores reconocidos a nivel internacional y presentándose desde muchas partes del mundo. Como académicos ubicados en la periferia de los centros académicos nacionales e internacionales, esperemos que esas transmisiones sigan aún después de la pandemia. 
Por otra parte, parece que el punto de partida, la inspiración, la motivación o el motor de nuestro trabajo de investigación, ha cambiado o, en parte, desaparecido. Si perdimos a la experiencia artística directa, ¿perdimos también a la investigación en artes?

Los investigadores - entre ellos principalmente los musicólogos tradicionalmente se han enfocado en las obras de arte guardadas en documentos escritos. En el caso de la música, la grabación audiovisual más bien ha formado un referente de apoyo y el intérprete y su interpretación han recibido poca atención. Pero para todos los investigadores que se interesan por las artes en su contexto sociocultural, los antropólogos, los investigadores de música, danza, teatro, arte popular, folklórico, indígena manifestándose en sus lugares y momentos específicos frente a un público, una parte de la sociedad, un grupo o una comunidad específica; a todos ellos la pandemia les ha recortado no solamente el acceso sino también una parte de su razón de ser.

Cerrando en referencia a lo expuesto por Andreas Reckwitz, nos preguntamos: Si perdemos al evento de arte en vivo - los conciertos, los performances, las puestas en escena, hasta las exposiciones de arte, etcétera - y, por consiguiente, la experiencia artística viva, ¿perdemos también a una parte de lo que nos define como sujetos en la actualidad?

Si bien es cierto que vivimos sorprendidos ahora por situaciones que nos parecen inéditas, también es cierto que ninguna de las ideas que hemos trazado son nuevas, sino se amplifican con la situación y nos hacen pensar, como señalamos en el epígrafe, "que nosotros los de entonces ya no somos los mismos".

\section{Referencias bibliográficas}

Blas-Lahitte, H., \& Sánchez-Vázquez, M. (2011). Aportes para una bioética medioambiental y cohabitabilidad humana desde la visión relacional. Pers. bioét., 15(1), 40-51.

Kennel, M. (2013). Dialectics unbound: on the possibility of total writing. NewYork: Punctum books

Kuhn, T. (1993). La tensión esencial. Estudios selectos sobre la tradición y el cambio en el ámbito de la ciencia (R. Helier, Trans.). Fondo de Cultura Económica-Conacyt: España.

Kuhn, T. (2000). La estructura de las revoluciones científicas (A. Contin, Trans.). Chile: Fondo de Cultura Económica.

Morín, E., Ciurana, R., \& Motta, R. (2006). Educar en la era planetaria, El pensamiento complejo como Método de aprendizaje en el error y la incertidumbre humana. España: Universidad de Valladolit-Unesco-IIPC-Usal.

Nussbaum, M. (2012). Crear capacidades. Propuesta para el desarrollo humano. Barcelona: Paidós.

Reckwitz Andreas (2020). The Society of Singularities. Cambridge: Polity Press.

Schechner, Richard (2012). Estudios de la representación. México: FCE.

Small, Christopher (1998). Musicking. The Meanings of Performing and Listening. Middletown: Wesleyan University Press.

Wallerstein, I. (2007). Impensar las ciencias sociales. Límites de los paradigmas decimonónicos (S. Guardado, Trans. 5a ed.). México: Siglo XXI editores.

Zemelman, H. (1992). Los horizontes de la razón: uso critico de la teoría. Dialéctica y apropiación del presente. Las funciones de la totalidad (Vol. 2). España: Anthropos.

Zemelman, H. (2005). Voluntad de conocer. El sujeto y su pensamiento en el paradigma critico (1a ed. Vol. 47). Barcelona: Anthropoa-CIH-UACH. 